\title{
Management of airway mucus hypersecretion in chronic airway inflammatory disease: Chinese expert consensus (English edition)
}

This article was published in the following Dove Press journal: International Journal of COPD

Yongchun Shen,' Shaoguang Huang, ${ }^{2}$ Jian Kang, ${ }^{3}$ Jiangtao Lin, ${ }^{4}$ Kefang Lai, ${ }^{5}$ Yongchang Sun, ${ }^{6}$ Wei Xiao, ${ }^{7}$ Lan Yang, ${ }^{8}$ Wanzhen Yao, ${ }^{6}$ Shaoxi Cai, ${ }^{9}$ Kewu Huang, ${ }^{10}$ Fuqiang Wen'

'Department of Respiratory and Critical Care Medicine, West China Hospital of Sichuan University and Division of Pulmonary Diseases, State Key Laboratory of Biotherapy of China, Chengdu, ${ }^{2}$ Department of Pulmonary Disease, Ruijin Hospital, Shanghai Jiao Tong University, Shanghai, ${ }^{3}$ Department of Respiratory Medicine, Institute of Respiratory Diseases, The First Affiliated Hospital of China Medical University, Shenyang, ${ }^{4}$ Department of Respiratory Diseases, China-Japan Friendship Hospital, Beijing, ${ }^{5}$ State Key Laboratory of Respiratory Disease, National Clinical Research Center for Respiratory Disease, Guangzhou Institute of Respiratory Diseases, First Affiliated Hospital of Guangzhou Medical University, Guangzhou, ${ }^{6}$ Department of Respiratory and Critical Care Medicine, Peking University Third Hospital, Beijing, ${ }^{7}$ Department of Respiratory Medicine, Qilu Hospital of Shandong University, Jinan, ${ }^{8}$ Department of Respiratory and Critical Care Medicine, The First Affiliated Hospital of Xi'an Jiaotong University, Xi'an, 'Department of Respiratory and Critical Care Medicine, Nanfang Hospital, Southern Medical University, Guangzhou, ${ }^{10}$ Division of Pulmonary and Critical Care Medicine, Beijing Chao-Yang Hospital, Capital Medica University, Beijing, People's Republic of China

Correspondence: Fuqiang Wen Department of Respiratory and Critical Care Medicine, West China Hospital of Sichuan University and Division of Pulmonary Diseases, State Key Laboratory of Biotherapy of China, No 37, Guo Xue Xiang, Chengdu 6I004I,

People's Republic of China

Tel +8628 85422350

Fax +862885582944

Email wenfuqiang.scu@gmail.com

\begin{abstract}
Airway mucus hypersecretion is one of the most important characteristics of chronic airway inflammatory diseases. Evaluating and managing airway mucus hypersecretion is of great importance for patients with chronic airway inflammatory diseases. This consensus statement describes the pathogenesis, clinical features, and the management of airway mucus hypersecretion in patients with chronic airway inflammatory diseases in the People's Republic of China. The statement has been written particularly for respiratory researchers, pulmonary physicians, and patients.
\end{abstract} Keywords: mucus, COPD, asthma, bronchiectasis, cystic fibrosis, treatment

\section{Introduction}

Airway mucus hypersecretion is an important pathophysiological and clinical manifestation of chronic obstructive pulmonary disease (COPD), bronchial asthma (asthma), bronchiectasis, pulmonary cystic fibrosis, and other chronic airway inflammatory diseases. ${ }^{1}$ Recent studies have shown that inflammation and oxidative stress are involved in the pathogenesis of chronic airway inflammatory diseases and closely correlate with clinical outcomes and that they trigger excessive mucus production and secretion by glands and goblet cells. The American Thoracic Society, European Respiratory Society, and Chinese Thoracic Society of the Chinese Medical Association have officially recognized that airway mucus hypersecretion plays an important role in common respiratory diseases. ${ }^{2-4}$

Reducing the risk of mortality and other complications associated with airway mucus hypersecretion means exploring its pathogenesis in detail, as well as clarifying its relationship with chronic airway inflammatory diseases. ${ }^{1-4}$ To take stock of available evidence and to guide both clinical practice and research initiatives, the COPD Group and Asthma Group of the Chinese Thoracic Society of the Chinese Medical Association have developed this consensus statement about the state of knowledge and best clinical practices for managing airway mucus hypersecretion induced by chronic airway inflammatory disease.

\section{Pathogenesis of airway mucus hypersecretion}

Mucus is the normal secretory product of the lining of the epithelium, which contains secreted water, sugar, protein, lipids, minerals, and mucins. Mucins are a group of proteins and the most important components of mucus, and MUC5AC and MUC5B are the 2 main mucins in mucus; the former is the main gel-forming mucin from surface mucus or goblet cells, and the latter is a primary secretory polymeric protein 
from submucosal glands. ${ }^{1,2}$ Under normal conditions, mucus secreted into the airway protects the airway and moistens the air. Under many types of stress conditions, including smoking, infection, pathogenic factors, and oxidative stress, cells lining the airway secrete numerous prosecretory factors that lead to secretory cell hypertrophy and goblet cell hyperplasia in the airway, with concomitant overproduction of mucus. ${ }^{1}$ COPD, asthma, and bronchiectasis involve airway mucus hypersecretion and ciliary dysfunction. In COPD, inflammatory responses induced by cigarette smoke and other stimulators, together with oxidative stress, injure airway epithelial cells and stimulate mucus hypersecretion. In bronchial asthma, oversecretion of mucin components MUC5AC and MUC5B in the airway, and damage to the epithelium, cause the exfoliation of ciliated cells, goblet cell hyperplasia, and submucosal gland hypertrophy, all of which ultimately lead to airway mucus hypersecretion. ${ }^{5}$ In bronchiectasis, irreversible expansion of the bronchial lumen compromises mucus clearance and allows bacteria to colonize the airway. The release of toxins secreted by bacteria first causes the activation of pathogen-associated molecular patterns and danger-associated molecular patterns to increase inflammation; this inflammation in turn stimulates goblet cell hyperplasia and metaplasia, leading to airway mucus hypersecretion. ${ }^{6-9}$

Various types of stimulation, such as cigarette smoking, induce abundant production of reactive oxygen species and proteases, which activate epidermal growth factor receptor, Toll receptor, and other receptors, in turn triggering multiple signaling pathways such as MAPK, ERK, and NF- $\kappa$ B. These pathways induce goblet cell metaplasia and hyperplasia in the airway, leading to synthesis and secretion of excessive mucin and thus to airway mucus hypersecretion. ${ }^{2-4}$ In this way, inflammation, oxidative stress, protease imbalances, cholinergic nerve dysfunction, and other pathophysiological mechanisms can influence the risk of airway mucus hypersecretion. In addition to environmental stimulants, genetic susceptibility factors can also influence such risk. ${ }^{10}$ For example, Chand et al reported that a genetic variant of p53 plays a role in determining chronic mucus hypersecretion. ${ }^{11}$ Such mucus hypersecretion can affect the clinical manifestations of COPD, bronchial asthma, bronchiectasis, and other common respiratory diseases.

\section{Airway mucus hypersecretion and chronic airway inflammatory disease}

Airway mucus hypersecretion can obstruct the respiratory tract lumen, limit airflow, and accelerate decline in lung function. ${ }^{12}$
At the same time, inflammatory responses compromise mucus clearance by cilia, remove alveolar surface active substances such as surfactants, and alter biophysical properties of mucus. ${ }^{13}$ This can lead to recurrent airway infection, causing further airway obstruction and remodeling, thereby creating a vicious cycle. Current evidence supports the notion that chronic inflammation causes mucus hypersecretion, which then plays a role in chronic airway inflammatory diseases.

\section{Airway mucus hypersecretion and COPD}

COPD is a common disease, the main clinical feature of which is persistent, progressive airflow limitation that is associated with chronic abnormal inflammatory responses to harmful particles or gases in the respiratory tract and lungs. ${ }^{14}$ COPD seriously affects patients' ability to work and their quality of life, and it is associated with high mortality. Large epidemiological surveys in the People's Republic of China indicate a COPD prevalence of $\sim 8.2 \%$ in adults aged $>40$ years. ${ }^{15}$

Airway mucus hypersecretion manifests clinically as chronic cough and expectoration. Individuals with such symptoms are nearly 3 times more likely to suffer COPD than healthy individuals, and these symptoms may be unrelated to smoking; indeed, paroxysmal cough is an independent risk factor for COPD. ${ }^{16,17}$ Patients with COPD have significantly more goblet cells in airway epithelium than controls, and they secrete significantly more mucoprotein; ${ }^{18}$ nearly $50 \%$ of COPD patients have airway mucus hypersecretion. ${ }^{19}$ Clogged airway by mucus leads to reduced airflow and then plays a role in the pathogenesis of COPD. COPD patients are at 3.5-fold greater risk of dying if they have airway mucus hypersecretion than if they do not. ${ }^{20}$

In patients with airway mucus hypersecretion and COPD, accelerated decline in lung function is associated with a high rate of hospitalization and acute exacerbation of COPD. Patients with chronic cough and expectoration exhibit a significantly higher incidence of acute exacerbation, which is mostly induced by bacterial and viral infection. ${ }^{21-23}$ The motions involved in chronic cough and expectoration may accelerate dynamic lung hyperinflation, which may help explain why chronic cough and expectoration are independent risk factors for reduced exercise capacity in COPD patients. ${ }^{24}$ In addition, among subjects with COPD, those with chronic mucus hypersecretion (chronic bronchitis phenotype) present worse quality of life symptoms and mental well-being than do those without chronic mucus hypersecretion. ${ }^{25}$

The important role of airway mucus hypersecretion in COPD should be fully recognized. ${ }^{26}$ Airway mucus 
hypersecretion, via chronic cough and expectoration, reduces airflow and exercise capacity and increases the risk of acute exacerbation, mortality, and poor prognosis in COPD patients.

\section{Airway mucus hypersecretion and bronchial asthma}

Bronchial asthma, often referred to simply as "asthma," is a chronic airway inflammatory disease, the main clinical feature of which is reversible airflow limitation. ${ }^{27}$ Those with asthma show obviously lower mucociliary clearance from airways than patients in controls. ${ }^{28}$ Approximately 20\%-40\% of patients have increased sputum volume and symptoms of airway mucus hypersecretion, and their airway mucus is more viscous than that in patients with COPD; in addition, their airways are easily obstructed by colloidal mucus plugs. ${ }^{29}$ Cough and expectoration are more obvious in moderate or severe asthma or uncontrollable asthma; these symptoms can serve as a phenotype and prognostic indicator. ${ }^{30,31}$ An autopsy study of 93 patients with fatal asthma found that nearly all had mucus-obstructed airways, leading investigators to conclude that asthma-related mortality, particularly among patients with severe asthma, may be due to airway mucus hypersecretion. ${ }^{32,33}$ The symptoms of asthma may be difficult to control because airway mucus hypersecretion facilitates bacterial colonization of airways, limits airflow, and compromises ventilation.

\section{Airway mucus hypersecretion and bronchiectasis}

Bronchiectasis is bronchial deformation and persistent bronchial expansion caused by the destruction of smooth muscles and elastic tissues on the bronchial wall due to chronic purulent inflammation and fibrosis of the bronchus and surrounding lung tissues. ${ }^{34}$ Cough occurs in $>90 \%$ of patients with bronchiectasis, and expectoration occurs as a complication in $75 \%-100 \%$ of patients with cough. Patients with bronchiectasis show reduced mucociliary activities in the airway and reduced expectoration ability, and the biophysical properties of their mucus are altered, eg, it is more viscous. ${ }^{35}$ The long-term accumulation of mucus in the airway facilitates colonization by bacteria as well as recurrent cough and expectoration..$^{35}$ In this way, airway mucus hypersecretion is a fundamental pathophysiological and clinical feature of bronchiectasis. Linked with airway mucus hypersecretion, airway inflammation and damage occur in bronchiectasis patients, seriously affecting patients' quality of life. ${ }^{36}$

\section{Airway mucus hypersecretion and pulmonary cystic fibrosis}

Pulmonary cystic fibrosis is a congenital lung disease often associated with mutation in the cystic fibrosis transmembrane conductance regulator, responsible for producing sweat, digestive juices, and various mucus fluids. ${ }^{37}$ Patients with pulmonary cystic fibrosis show severe airway mucus hypersecretion, and many suffer recurrent pulmonary infections, which can accelerate decline in the lung function. Patient sputum is characterized by obvious neutrophil infiltration, cellular DNA released from injured cells, and abundant Pseudomonas aeruginosa. ${ }^{38}$ Patients also show substantial epithelial goblet cell metaplasia in the airway in contrast to healthy individuals, as well as significantly higher MUC5AC expression. ${ }^{38}$ Airway mucus hypersecretion in patients with pulmonary cystic fibrosis is associated with persistent cough, expectoration, and dyspnea.

The preceding sections summarize the close relationship of airway mucus hypersecretion with incidence, progression, and prognosis of common chronic airway inflammatory diseases. Full recognition of the role of airway mucus hypersecretion in these diseases is important for guiding clinical treatment.

\section{Evaluation of airway mucus hypersecretion}

Airway mucus hypersecretion manifests mainly as chronic cough and expectoration, which are particularly obvious during stimulation, weather changes, and exacerbation of infection. The severity of cough and the volume and properties of sputum serve as an index of airway mucus hypersecretion, which can fluctuate during periods of stability or acute exacerbation of airway diseases. The cough and sputum assessment questionnaire (CASA-Q) designed by Crawford et al is one of the few tools available for assessing airway mucus hypersecretion..$^{39}$ The questionnaire contains 4 sections covering coughing, sputum, and their effects. Lower overall score indicates more severe airway mucus hypersecretion. CASA-Q score is closely related to the quality of life and clinical symptoms of COPD patients, and it is useful for monitoring recovery from acute COPD exacerbations. ${ }^{39,40}$ In addition, $\mathrm{St}$ George's Respiratory Questionnaire and American Thoracic Society Questionnaire, important questionnaires that are used for many cohorts around the world and also contain questions for evaluation of cough and sputum, can also be used to evaluate airway mucus hypersecretion. ${ }^{41,42}$ All these questionnaires may be used to evaluate airway mucus hypersecretion and to define the questionnaire with best efficacy. No standardized methods exist for quantitating airway mucus hypersecretion in COPD patients, which requires invasive procedures and so is rarely performed in the clinic. Since cough and expectoration 
frequently occur in many respiratory diseases, future research should seek to clarify the differences in features of airway mucus hypersecretion caused by different diseases, in order to ensure accurate diagnosis and management.

\section{Treatment of airway mucus hypersecretion}

At present, chronic airway inflammatory diseases such as COPD and asthma are treated mainly using bronchodilators to open occluded airways or by using corticosteroid inhalation to control inflammation. ${ }^{2-4}$ Given the important clinical significance of airway mucus hypersecretion in chronic airway inflammatory diseases, expectorant therapy is widely used to help relieve airway stenosis, avoid recurrent infection and exacerbation, and delay decline in lung function.

\section{Drug therapies (expectorants)}

Expectorants are drugs that promote mucus activity, alter mucus viscosity, and/or promote mucus clearance. ${ }^{43}$ Drugs promoting mucus activity can be classified into the following categories (Table 1): 1) expectorants that remove mucus from the respiratory tract (hypertonic normal saline and woundhealing glycerol ether); 2) mucoregulators that alter mucus secretion (carbocysteine and macrolides); 3) mucolytics that reduce mucus viscosity ( $\mathrm{N}$-acetylcysteine, erdosteine, and fudosteine); and 4) mucokinetic agents (bronchodilators, myrtle oil, and ambroxol). Each category is discussed in more detail below.

\section{Expectorants}

Hypertonic saline helps clear sputum, and administering $7 \%$ hypertonic saline to patients with pulmonary cystic fibrosis accelerates mucus discharge and improves airflow and lung function. ${ }^{44,45}$ Aerosol inhalation of $7 \%$ hypertonic saline as an auxiliary therapy can promote mucus discharge and improve lung function and quality of life in patients with bronchiectasis. ${ }^{46}$ Studies in mouse models of COPD suggest that hypertonic saline can help prevent and treat airway mucus hypersecretion, but its value in patients remains to be demonstrated ${ }^{47}$ Further study has shown that some COPD patients suffer further airway stenosis while receiving 3\% hypertonic saline. ${ }^{48}$ In fact, patients with different types of chronic airway inflammatory diseases respond differently to hypertonic saline, and especially some COPD patients develop dyspnea when receiving atomizing hypertonic saline. ${ }^{48}$ Therefore, hypertonic saline treatment should be used in accordance with its clinical indications.
Table I Mucoactive drugs and their potential mechanism of action

\begin{tabular}{|c|c|}
\hline Mucoactive drugs & Potential mechanism of action \\
\hline \multicolumn{2}{|l|}{ Expectorants } \\
\hline Hypertonic saline & Increases secretion volume and/or hydration \\
\hline Guaifenesin & Stimulates secretion and reduces mucus viscosity \\
\hline \multicolumn{2}{|l|}{ Mucus regulators } \\
\hline Carbocysteine & $\begin{array}{l}\text { Metabolism of mucus-producing cells, } \\
\text { antioxidant and anti-inflammatory effects, } \\
\text { modulates mucus production }\end{array}$ \\
\hline Anticholinergic agents & Decrease secretion volume \\
\hline Glucocorticoids & $\begin{array}{l}\text { Reduce airway inflammation and mucin } \\
\text { secretion }\end{array}$ \\
\hline Macrolide antibiotics & $\begin{array}{l}\text { Reduce airway inflammation and mucin } \\
\text { secretion }\end{array}$ \\
\hline \multicolumn{2}{|l|}{ Mucolytics } \\
\hline $\mathrm{N}$-acetylcysteine & $\begin{array}{l}\text { Breaks disulfide bonds linking mucin polymers, } \\
\text { antioxidant and anti-inflammatory effects }\end{array}$ \\
\hline Nacystelyn & Increases chloride secretion and disulfide bonds \\
\hline Erdosteine & $\begin{array}{l}\text { Modulates mucus production and increases } \\
\text { mucociliary transport }\end{array}$ \\
\hline Dornase alfa & $\begin{array}{l}\text { Hydrolyzes the DNA in mucus and reduces } \\
\text { viscosity in the lungs }\end{array}$ \\
\hline Gelsolin & Severs actin filament cross-links \\
\hline Thymosin $\beta_{4}$ & Severs actin filament cross-links \\
\hline Dextran & $\begin{array}{l}\text { Breaks hydrogen bonds and increases secretion } \\
\text { hydration }\end{array}$ \\
\hline Heparin & Breaks hydrogen bonds and ionic bonds \\
\hline \multicolumn{2}{|l|}{ Mucokinetics } \\
\hline Bronchodilators & $\begin{array}{l}\text { Improve cough clearance by increasing } \\
\text { expiratory flow }\end{array}$ \\
\hline Surfactants & Decrease sputum/mucus adhesiveness \\
\hline Ambroxol & $\begin{array}{l}\text { Stimulates surfactant production and inhibits } \\
\text { neuronal sodium channels }\end{array}$ \\
\hline
\end{tabular}

Note: Reproduced with permission from the (C) ERS 2010. European Respiratory Review Jun 2010, 19(1 16):127-133; DOI: 10.1 183/09059180.00003510.43

\section{Mucoregulators}

A multicenter study involving a 1-year follow-up published in 2008 reported that carbocysteine ( $500 \mathrm{mg}, 3$ times daily) significantly reduced the frequency of acute COPD exacerbations and that health-related quality of life was significantly higher in COPD patients than in controls. ${ }^{49}$ Another study supported the idea that carbocysteine can significantly reduce the frequency of acute exacerbations, reduce the frequency of catching colds, and improve the quality of life in COPD patients. ${ }^{50}$ As a result, carbocysteine is the drug recommended by the Global Initiative for Chronic Obstructive Lung Disease (GOLD) for treating COPD. Carbocysteine (500 mg, 3 times daily) can also improve the cough threshold and relieve cough symptoms in asthma patients, and it is the recommended treatment for cough-variant asthma. ${ }^{51}$

Macrolides, in addition to their antibacterial activity, show good immunomodulatory activity and can inhibit inflammation and airway mucus hypersecretion. ${ }^{52}$ Long-term 
administration of erythromycin (250 mg, twice daily), azithromycin ( $250 \mathrm{mg}$, once daily), and other macrolides helps reduce the frequency of acute exacerbations in COPD patients and improves their quality of life, and evidencebased medicine has also confirmed the clinical value of macrolides for reducing the occurrence of acute COPD exacerbations. ${ }^{53-55}$ Although no official guidelines include macrolides among classical expectorants, the available evidence suggests that macrolides can be recommended for achieving antibiotic effects and sputum clearance in COPD patients who require antibiotics. ${ }^{56}$ Evidence also suggests that macrolides have limited ability to improve lung function, but they can improve airway hyperresponsiveness in asthma patients. ${ }^{57}$ In bronchiectasis patients, the macrolides erythromycin ( $250 \mathrm{mg}$, twice daily after conversion) and azithromycin ( $250 \mathrm{mg}$, once daily) can help alleviate acute exacerbations in patients with infective COPD. ${ }^{58,59}$ The combination of roxithromycin (150 mg, once daily) and ambroxol can improve bronchiectasis and dyspnea scores in the stable phase of the disease. ${ }^{60}$ The available evidence suggests that macrolides help reverse the exacerbation of pulmonary symptoms in bronchiectasis patients ${ }^{61}$ Macrolides can be recommended for long-term use in some bronchiectasis patients with severe symptoms of airway mucus hypersecretion; these patients benefit from the compounds' dual effects as antibiotics and immunomodulators.

\section{Mucolytics}

$\mathrm{N}$-acetylcysteine is a classic antioxidant that can reduce mucus viscosity and promote mucus discharge. ${ }^{62}$ In COPD patients, high-dose $\mathrm{N}$-acetylcysteine (600 mg, twice daily) can significantly improve lung function, reduce the frequency of acute COPD exacerbations, delay readmission, and enhance small airway function. ${ }^{63} \mathrm{~A}$ randomized controlled trial of 1,006 patients aged 40-80 years and treated at 34 Chinese hospitals for moderate or severe COPD confirmed that long-term, high-dose $\mathrm{N}$-acetylcysteine $(600 \mathrm{mg}$, twice daily) can effectively prevent acute COPD exacerbations. ${ }^{64}$ Even patients with moderate COPD benefited significantly. GOLD indicates that $\mathrm{N}$-acetylcysteine can be used to prevent acute COPD exacerbations. Little evidence exists for or against the use of $\mathrm{N}$-acetylcysteine in patients with asthma, pulmonary cystic fibrosis, or bronchiectasis; large, rigorous trials are needed to examine safety and efficacy in these populations.

Erdosteine, another mucolytic, can promote mucus discharge and improve lung function in elderly patients with bronchiectasis and chronic airway mucus hypersecretion. ${ }^{65}$
Fudosteine is used to treat chronic respiratory diseases, such as bronchial asthma, chronic bronchitis, pulmonary emphysema, COPD, and bronchiectasis. It works as a mucoactive agent by inhibiting MUC5AC gene expression and related signaling pathways. ${ }^{66,67}$ Fudosteine has been shown to inhibit peroxynitrite-induced airway nitrosative stress in lung epithelial cells by direct scavenging of peroxynitrite and plays a protective role in COPD. ${ }^{68}$ These findings suggest that fudosteine may be useful for controlling oxidative/carbonyl stress-related mucus secretion in patients with asthma, bronchiectasis, or COPD. ${ }^{69}$

\section{Mucokinetic agents}

The prokinetic agent most widely used in the clinic is ambroxol, which can stimulate surfactant production in the respiratory tract, regulate secretion of serous and mucus fluids, improve mucus clearance in the ciliated and nonciliated areas of the respiratory tract, reduce phlegm and ciliary adhesion, and facilitate expectoration..$^{70}$ Long-term ambroxol (75 mg, twice daily) can reduce the frequency of acute exacerbations in patients with severe COPD ${ }^{71}$ It can also benefit patients who experience acute exacerbations by alleviating oxidative stress reactions. ${ }^{72}$ Recent work suggests that ambroxol can work synergistically with antibiotics in a rat model of catheter-associated $P$. aeruginosa infection. ${ }^{73}$ Oral and injected ambroxol can be used in COPD outpatients and inpatients receiving expectorant therapy, particularly those with viscous sputum and expectoration difficulties. The usual dose is $30 \mathrm{mg}, 3$ times daily; this can be adjusted based on clinical conditions. Ambroxol can improve lung function and shorten hospitalization for bronchiectasis patients with infections. ${ }^{74}$ The main components of myrtle oil expectorants are eucalyptol and limonene; they also contain pinene and standard myrtle oil. Standard myrtle oil can restore mucociliary clearance in the upper and lower respiratory tracts, thereby thinning and alkalifying mucus, enhancing mucociliary movement, significantly accelerating mucus motility, and promoting sputum discharge in a rat model of COPD. ${ }^{75}$ The combination of standard myrtle oil and routine treatment has been shown to accelerate mucus motility in COPD patients more than routine treatment on its own, as well as improve blood gas composition. ${ }^{76}$ Myrtle oil is often used as an expectorant for COPD patients with expectoration difficulties (eucalyptol-limonene-pinene at $300 \mathrm{mg}, 2-3$ times daily; standard myrtle oil at $300 \mathrm{mg}$, 3 times daily).

Bronchodilators dilate the bronchus and reduce mucus secretion. The bronchodilator tiotropium bromide, which is 
an anticholinergic agent, can effectively suppress goblet cell metaplasia induced by neutrophil elastase and mucin secretion; this implies that its therapeutic effects may involve suppressing airway mucus hypersecretion in mice; thus, tiotropium bromide can also be classified as a mucus regulator. ${ }^{77}$ Consistent with this idea, formoterol, one of the long-acting $\beta_{2}$-receptor agonists, may inhibit airway goblet cell hyperplasia and MUC5AC expression and reduce airway mucus hypersecretion in asthmatic mice. ${ }^{78}$ The combination of $\beta_{2}$ agonist formoterol and tiotropium bromide can accelerate airway mucus clearance, dilate the bronchus, alleviate airway stenosis, suppress mucin synthesis, and promote ciliary motions and mucus discharge in COPD patients. ${ }^{79}$ Respiratory wards in hospitals have begun routinely combining bronchodilators and expectorants to treat COPD. In the People's Republic of China, acute COPD exacerbations are routinely treated using the combination of aerosol inhalation of isopropyl bromide and intravenous injection of ambroxol. This treatment promotes sputum discharge, alleviates symptoms of airway obstruction such as hypoxia and dyspnea, and increases clinical efficacy in patients with acute COPD exacerbation. ${ }^{80}$

A systematic review of 30 clinical studies involving 7,436 subjects concluded that expectorants can reduce the frequency of acute COPD exacerbations, benefiting COPD patients with a phenotype of frequent exacerbations and patients who are repeatedly admitted to hospital. ${ }^{81}$ In contrast, a large evidence base is lacking about the efficacy of expectorants in treating asthma, pulmonary cystic fibrosis, and bronchiectasis. Future studies should assess efficacy of expectorants.

\section{Nondrug therapies}

Several nondrug therapies have been described for managing patients with chronic airway inflammatory disease and associated airway mucus hypersecretion. One therapy is smoking cessation, since tobacco smoke is one of the strongest risk factors for various respiratory diseases, including COPD and asthma. Toxic ingredients in tobacco smoke may stimulate epithelial goblet cell metaplasia in the airway as well as mucin secretion, leading to airway mucus hypersecretion. Smoking cessation may therefore cut off airway mucus hypersecretion "at the source." In the People's Republic of China, national guidelines have been published to guide efforts by health care workers to help patients stop smoking. ${ }^{82}$

Another nondrug therapy is physiotherapy, in which patients are taught about deep breathing and effective coughing, or they receive chest percussion, postural expectoration, and inhalation therapies. Inhalation therapies, which can be administered via humidified inhalation or aerosol inhalation, can moisturize the airway, dilute sputum, facilitate expectoration, and prevent sputum scab formation. Such therapies are widely used to treat common respiratory tract diseases because they provide obvious benefits with few, if any, adverse reactions. ${ }^{83}$

Effective mucus discharge requires different body positions depending on the site of a patient's lesion, ${ }^{84}$ and this postural drainage must be taught to patients. Appropriate body positions help the mucus flow from focus to large airway then to bronchus and help to get mucus out of the airway, and then, they play a role in mucus discharge. Patients with lesions in the right upper apical segment should expectorate while sitting in a vertical or inclined position and leaning slightly to the left. Patients with lesions in the right upper anterior segment should expectorate while supine with the right back slightly elevated. Patients with lesions in the right upper posterior segment should expectorate while in a left supine position and turning left by $45^{\circ}$, with a cushion placed in front to support the posture. Patients with lesions in the right middle segment should expectorate while supine with the chest and abdomen turned to the left by $45^{\circ}$, with a cushion placed behind to support the posture and with the right end of the bed elevated. Patients with lesions in the left upper posterior apical segment should expectorate while in the vertical sitting position or semi-supine position, with the body leaning to the right by $45^{\circ}$ and with a cushion placed behind to support the posture. Patients with lesions in the left upper anterior segment and lingular segment should be supine, with the chest and abdomen turned to the right by $45^{\circ}$, with a cushion placed behind to support the posture and the left end of the bed elevated. Patients with lesions in the left lower dorsal segment should be prone, leaning slightly with the affected side upward and the head lowered. Patients with lesions in the left lower basal segment should be prone, leaning by $45^{\circ}$ with the affected side upward, the head downward, and the chest upward; alternatively, they can adopt a contralateral supine position with the chest and abdomen turned to the right by $45^{\circ}$, the head lowered and facing downward and the feet pointing upward (Figure 1).

A third nondrug therapy is high-frequency chest wall oscillation. This is often used to enhance airway mucus clearance in patients with pulmonary cystic fibrosis and bronchiectasis, and it can significantly improve the quality of life in COPD patients and reduce sputum volume. ${ }^{85}$ Intermittent positive end-expiratory pressure (PEEP) can dilate the small airway, reduce small airway obstruction, promote the sputum drainage and discharge, and accelerate mucus clearance in COPD patients. Performing PEEP twice daily for 15 minutes each time during 10 days can promote expectoration and 


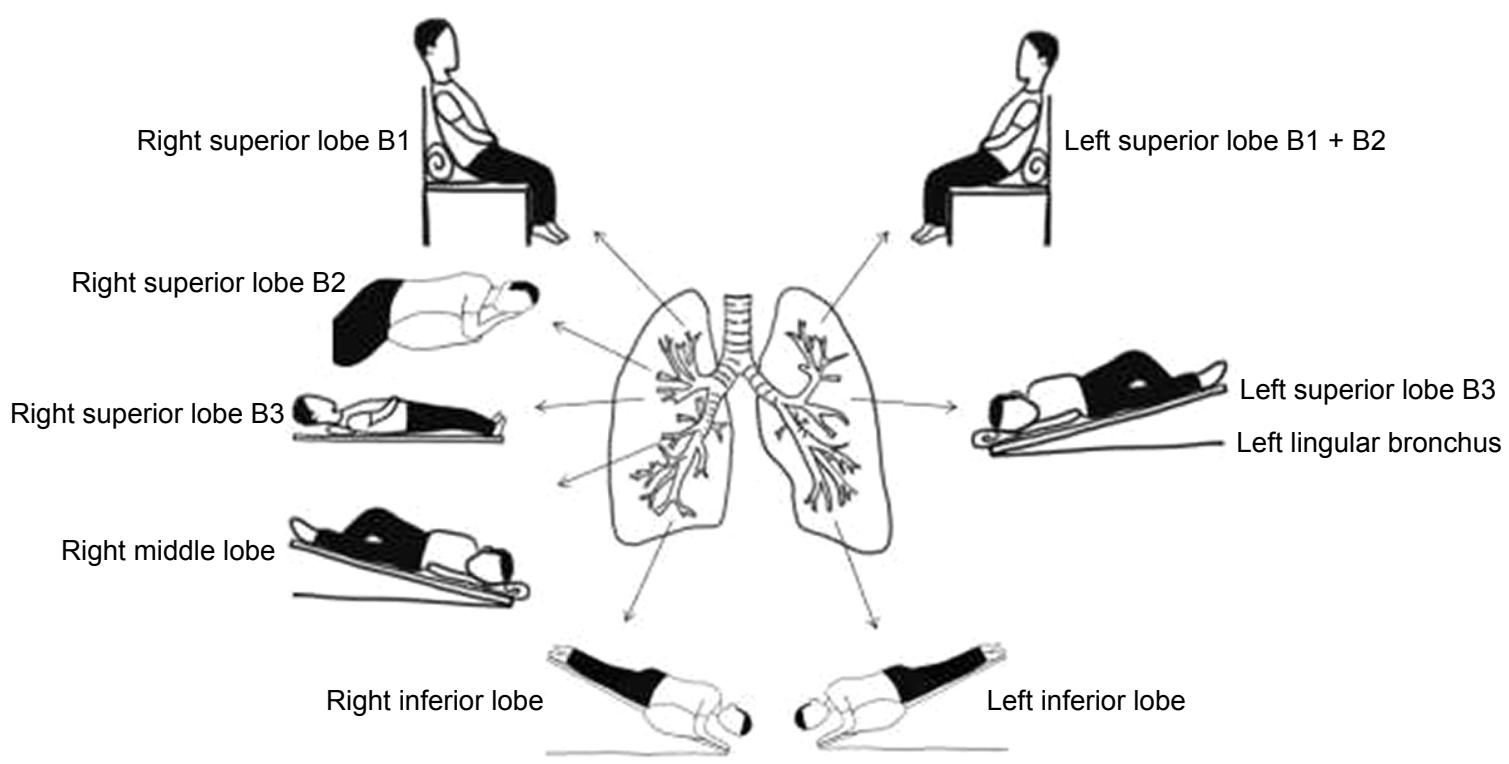

Figure I The sketch map of body positions for postural drainage.

Notes: BI, apical segment; B2, anterior segment; B3, posterior segment.

reduce mucus density and production of purulent sputum; therefore, it may be useful for COPD patients with symptoms of airway mucus hypersecretion. ${ }^{86}$

\section{Future studies and expectations}

Airway mucus hypersecretion is an important driver of airway obstruction, rapid decline in lung function, and increased frequency of acute exacerbation in patients with chronic airway inflammatory diseases; it is closely related to patient prognosis. Detailed investigation into the signaling pathways and downstream effector molecules involved in airway mucus hypersecretion will improve our understanding and the treatment of these chronic diseases. One challenge is to systematically explore how to combine traditional drugs with classic expectorants and how to combine expectorants to achieve optimal therapeutic effects. Clinicians should recognize the benefits of expectorant therapies for patients with chronic airway inflammatory diseases and should continuously seek to improve and innovate treatments for such patients.

\section{Acknowledgments}

This work was supported by National Key Research and Development Program (2016YFC0903600 and 2016YFC1304500), National Natural Science Foundation of China (81230001, 81470236 and 81670038), and the Science and Technology Pillar Program of the Department of Science and Technology of Sichuan province (2015SZ0151). The funders had no role in study design, data collection or analysis, decision to publish, and manuscript preparation. We also express our sincere thanks to the European Respiratory Society for its generosity in supplying the copyright transfer of Table 1 to help spread scientific knowledge.

\section{Disclosure}

The authors report no conflicts of interest in this work.

\section{References}

1. Fahy JV, Dickey BF. Airway mucus function and dysfunction. $N$ Engl J Med. 2010;363(23):2233-2247.

2. Curran DR, Cohn L. Advances in mucous cell metaplasia: a plug for mucus as a therapeutic focus in chronic airway disease. Am J Respir Cell Mol Biol. 2010;42(3):268-275.

3. Cerveri I, Brusasco V. Revisited role for mucus hypersecretion in the pathogenesis of COPD. Eur Respir Rev. 2010;19(116):109-112.

4. Wen FQ, Shen YC. [Expectorant therapy revisited in chronic obstructive pulmonary disease]. Zhonghua Jie He He Hu Xi Za Zhi. 2011; 34(4):243-245. Chinese.

5. Rogers DF. Mucoactive agents for airway mucus hypersecretory diseases. Respir Care. 2007;52(9):1176-1193.

6. Henson PM. Dampening inflammation. Nat Immunol. 2005;6(12) 1179-1181.

7. Korfhagen TR, Kitzmiller J, Chen G, et al. SAM-pointed domain ETS factor mediates epithelial cell-intrinsic innate immune signaling during airway mucous metaplasia. Proc Natl Acad Sci U S A. 2012; 109(41):16630-16635.

8. Holtzman MJ, Byers DE, Alexander-Brett J, Wang X. The role of airway epithelial cells and innate immune cells in chronic respiratory disease. Nat Rev Immunol. 2014;14(10):686-698.

9. Tyner JW, Kim EY, Ide K, et al. Blocking airway mucous cell metaplasia by inhibiting EGFR antiapoptosis and IL-13 transdifferentiation signals. J Clin Invest. 2006;116(2):309-321.

10. Dijkstra AE, Boezen HM, van den Berge M, et al. Dissecting the genetics of chronic mucus hypersecretion in smokers with and without COPD. Eur Respir J. 2015;45(1):60-75.

11. Chand HS, Montano G, Huang X, et al. A genetic variant of p53 restricts the mucous secretory phenotype by regulating SPDEF and Bcl-2 expression. Nat Commun. 2014;5:5567. 
12. Allinson JP, Hardy R, Donaldson GC, Shaheen SO, Kuh D, Wedzicha JA. The presence of chronic mucus hypersecretion across adult life in relation to chronic obstructive pulmonary disease development. Am J Respir Crit Care Med. 2016;193(6):662-672.

13. Reid KB, Clark H, Palaniyar N. Surfactant and lung inflammation. Thorax. 2005;60(8):620-622.

14. COPD group of Chinese Thoracic Society. [Guideline for diagnosis and treatment of chronic obstructive pulmonary disease (updated 2013)]. Zhonghua Jie He He Hu Xi Za Zhi. 2013;36(4):255-265. Chinese.

15. Zhong N, Wang C, Yao W, et al. Prevalence of chronic obstructive pulmonary disease in China: a large, population-based survey. Am J Respir Crit Care Med. 2007;176(8):753-760.

16. de Marco R, Accordini S, Cerveri I, et al. Incidence of chronic obstructive pulmonary disease in a cohort of young adults according to the presence of chronic cough and phlegm. Am J Respir Crit Care Med. 2007;175(1):32-39.

17. Yamane T, Hattori N, Kitahara Y, et al. Productive cough is an independent risk factor for the development of COPD in former smokers. Respirology. 2010;15(2):313-318.

18. Ma R, Wang Y, Chen G, Zhang HZ, Wan HY, Huang SG. [Goblet cell hyperplasia and abnormalities in mucin expression in COPD patients]. Shanghai Di Er Yi Ke Da Xue Xue Bao. 2004;24(12):1031-1033, 1044. Chinese.

19. Miravitlles M, Guerrero T, Mayordomo C, Sánchez-Agudo L, Nicolau F, Segú JL. Factors associated with increased risk of exacerbation and hospital admission in a cohort of ambulatory COPD patients: a multiple logistic regression analysis. The EOLO Study Group. Respiration. 2000;67(5):495-501.

20. Hogg JC, Chu FS, Tan WC, et al. Survival after lung volume reduction in chronic obstructive pulmonary disease: insights from small airway pathology. Am J Respir Crit Care Med. 2007;176(5):454-459.

21. Burgel PR, Nesme-Meyer P, Chanez P, et al. Cough and sputum production are associated with frequent exacerbations and hospitalizations in COPD subjects. Chest. 2009;135(4):975-982.

22. Wedzicha JA, Singh R, Mackay AJ. Acute COPD exacerbations. Clin Chest Med. 2014;35(1):157-163.

23. Wedzicha JA. Mechanisms of chronic obstructive pulmonary disease exacerbations. Ann Am Thorac Soc. 2015;12(Suppl 2):S157-S159.

24. Zhang W, Lu H, Peng L, et al. Chronic bronchitis leads to accelerated hyperinflation in COPD patients during exercise. Respirology. 2015; 20(4):618-625.

25. Meek PM, Petersen H, Washko GR, et al. Chronic bronchitis is associated with worse symptoms and quality of life than chronic airflow obstruction. Chest. 2015;148(2):408-416.

26. Miravitlles M. Cough and sputum production as risk factors for poor outcomes in patients with COPD. Respir Med. 2011;105(8):1118-1128.

27. Asthma Workgroup, Chinese Thoracic Society, Chinese Society of General Practitioners. Chinese guideline for the prevention and management of bronchial asthma (Primary Health Care Version). J Thorac Dis. 2013;5(5):667-677.

28. Del Donno M, Bittesnich D, Chetta A, Olivieri D, Lopez-Vidriero MT. The effect of inflammation on mucociliary clearance in asthma: an overview. Chest. 2000;118(4):1142-1149.

29. de Marco R, Marcon A, Jarvis D, et al. Prognostic factors of asthma severity: a 9-year international prospective cohort study. J Allergy Clin Immunol. 2006;117(6):1249-1256.

30. Thomson NC, Chaudhuri R, Messow CM, et al. Chronic cough and sputum production are associated with worse clinical outcomes in stable asthma. Respir Med. 2013;107(10):1501-1508.

31. Siroux V, Boudier A, Bousquet J, et al. Phenotypic determinants of uncontrolled asthma. J Allergy Clin Immunol. 2009;124(4):681-687.e3.

32. Kuyper LM, Paré PD, Hogg JC, et al. Characterization of airway plugging in fatal asthma. Am J Med. 2003;115(1):6-11.

33. Aikawa T, Shimura S, Sasaki H, Ebina M, Takishima T. Marked goblet cell hyperplasia with mucus accumulation in the airways of patients who died of severe acute asthma attack. Chest. 1992;101(4):916-921.
34. Workgroup of bronchiectasis diagnosis and management. [Expert consensus on diagnosis and management of adult bronchiectasis]. Zhonghua Jie He He Hu Xi Za Zhi. 2012;35(7):485-492. Chinese.

35. Tambascio J, de Souza HC, Martinez JA, Afonso JL, Jardim JR, Gastaldi AC. The influence of purulence on ciliary and cough transport in bronchiectasis. Respir Care. 2013;58(12):2101-2106.

36. Goeminne PC, Vandooren J, Moelants EA, et al. The Sputum Colour Chart as a predictor of lung inflammation, proteolysis and damage in non-cystic fibrosis bronchiectasis: a case-control analysis. Respirology. 2014;19(2):203-210.

37. Liu TW, Kang J. [Analysis of clinical features of cystic fibrosis in Chinese]. Zhong Guo Quan Ke Yi Xue. 15(24):2807-2810. Chinese.

38. Kreda SM, Davis CW, Rose MC. CFTR, mucins, and mucus obstruction in cystic fibrosis. Cold Spring Harb Perspect Med. 2012;2(9):a009589.

39. Crawford B, Monz B, Hohlfeld J, et al. Development and validation of a cough and sputum assessment questionnaire. Respir Med. 2008; 102(11):1545-1555.

40. Monz BU, Sachs P, McDonald J, Crawford B, Nivens MC, Tetzlaff K. Responsiveness of the cough and sputum assessment questionnaire in exacerbations of COPD and chronic bronchitis. Respir Med. 2010; 104(4):534-541.

41. Hardin M, Rennard SI. What's new with the St George's Respiratory Questionnaire and why do we care? Chronic Obstr Pulm Dis. 2017; 4(2):83-86.

42. Cassidy RN, Roberts ME, Colby SM. Validation of a respiratory symptom questionnaire in adolescent smokers. Tob Regul Sci. 2015; 1(2):121-128.

43. Balsamo R, Lanata L, Egan CG. Mucoactive drugs. Eur Respir Rev. 2010; 19(116):127-133.

44. Donaldson SH, Bennett WD, Zeman KL, Knowles MR, Tarran R, Boucher RC. Mucus clearance and lung function in cystic fibrosis with hypertonic saline. $N$ Engl J Med. 2006;354(3):241-250.

45. Elkins MR, Robinson M, Rose BR, et al. A controlled trial of long-term inhaled hypertonic saline in patients with cystic fibrosis. $N$ Engl J Med. 2006;354(3):229-240.

46. Kellett F, Robert NM. Nebulised 7\% hypertonic saline improves lung function and quality of life in bronchiectasis. Respir Med. 2011; 105(12):1831-1835.

47. Graeber SY, Zhou-Suckow Z, Schatterny J, Hirtz S, Boucher RC, Mall MA. Hypertonic saline is effective in the prevention and treatment of mucus obstruction, but not airway inflammation, in mice with chronic obstructive lung disease. Am J Respir Cell Mol Biol. 2013; 49(3):410-417.

48. Taube C, Holz O, Mücke M, Jörres RA, Magnussen H. Airway response to inhaled hypertonic saline in patients with moderate to severe chronic obstructive pulmonary disease. Am J Respir Crit Care Med. 2001;164(10 Pt 1):1810-1815.

49. Zheng JP, Kang J, Huang SG, et al. Effect of carbocisteine on acute exacerbation of chronic obstructive pulmonary disease (PEACE Study): a randomised placebo-controlled study. Lancet. 2008;371(9629): 2013-2018.

50. Yasuda H, Yamaya M, Sasaki T, et al. Carbocisteine reduces frequency of common colds and exacerbations in patients with chronic obstructive pulmonary disease. J Am Geriatr Soc. 2006;54(2):378-380.

51. Ishiura Y, Fujimura M, Yamamori C, et al. Effect of carbocysteine on cough reflex to capsaicin in asthmatic patients. Br J Clin Pharmacol. 2003;55(6):504-510.

52. Ling L, Lin JT. [Anti-inflammatory role of macrolides on respiratory diseases]. Zhong Ri You Hao Yi Yuan Xue Bao. 2009;23(4):247-253. Chinese.

53. Seemungal TA, Wilkinson TM, Hurst JR, Perera WR, Sapsford RJ, Wedzicha JA. Long-term erythromycin therapy is associated with decreased chronic obstructive pulmonary disease exacerbations. Am J Respir Crit Care Med. 2008;178(11):1139-1147.

54. Albert RK, Connett J, Bailey WC, et al. Azithromycin for prevention of exacerbations of COPD. N Engl J Med. 2011;365(8):689-698. 
55. Yao GY, Ma YL, Zhang MQ, Gao ZC. Macrolide therapy decreases chronic obstructive pulmonary disease exacerbation: a meta-analysis. Respiration. 2013;86(3):254-260.

56. Spagnolo P, Fabbri LM, Bush A. Long-term macrolide treatment for chronic respiratory disease. Eur Respir J. 2013;42(1):239-251.

57. Reiter J, Demirel N, Mendy A, et al. Macrolides for the long-term management of asthma - a meta-analysis of randomized clinical trials. Allergy. 2013;68(8):1040-1049.

58. Serisier DJ, Martin ML, McGuckin MA, et al. Effect of long-term, lowdose erythromycin on pulmonary exacerbations among patients with non-cystic fibrosis bronchiectasis: the BLESS randomized controlled trial. JAMA. 2013;309(12):1260-1267.

59. Altenburg J, de Graaff CS, Stienstra Y, et al. Effect of azithromycin maintenance treatment on infectious exacerbations among patients with non-cystic fibrosis bronchiectasis: the BAT randomized controlled trial. JAMA. 2013;309(12):1251-1259.

60. Liu JF, Zhong XN, He ZY, et al. [Impact of treatment with low dose roxithromycin on stable bronchiectasis]. Zhonghua Jie He He Hu Xi Za Zhi. 2012;35(11):824-827. Chinese.

61. Shi ZL, Peng H, Hu XW, Hu JG. Effectiveness and safety of macrolides in bronchiectasis patients: a meta-analysis and systematic review. Pulm Pharmacol Ther. 2014;28(2):171-178.

62. Liu SX, Yang L. [Effect of N-acetylcysteine on SOD, MDA in COPD patients with different stages]. Zhong Guo Lao Nian Xue Za Zhi. 2006;26(8):1028-1029. Chinese.

63. Tse HN, Raiteri L, Wong KY, et al. High-dose N-acetylcysteine in stable COPD: the 1-year, double-blind, randomized, placebo-controlled HIACE study. Chest. 2013;144(1):106-118.

64. Zheng JP, Wen FQ, Bai CX, et al. Twice daily N-acetylcysteine $600 \mathrm{mg}$ for exacerbations of chronic obstructive pulmonary disease (PANTHEON): a randomised, double-blind placebo-controlled trial. Lancet Respir Med. 2014;2(3):187-194.

65. Zhou BQ, Li XK. [Clinic efficacy of erdosteine on elderly bronchiectasis patients with airway mucus hypersecretion]. Shi Yong Yi Xue Za Zhi. 2011;27(6):1066-1068. Chinese.

66. Rhee CK, Kang CM, You MB, et al. Effect of fudosteine on mucin production. Eur Respir J. 2008;32(5):1195-1202.

67. Ueno-Iio T, Shibakura M, Iio K, et al. Effect of fudosteine, a cysteine derivative, on airway hyperresponsiveness, inflammation, and remodeling in a murine model of asthma. Life Sci. 2013;92(20-21):1015-1023.

68. Osoata GO, Hanazawa T, Brindicci C, Ito M, et al. Peroxynitrite elevation in exhaled breath condensate of COPD and its inhibition by fudosteine. Chest. 2009;135(6):1513-1520.

69. Rahman I, MacNee W. Antioxidant pharmacological therapies for COPD. Curr Opin Pharmacol. 2012;12(3):256-265.

70. Malerba M, Ragnoli B. Ambroxol in the 21st century: pharmacological and clinical update. Expert Opin Drug Metab Toxicol. 2008;4(8): 1119-1129.

71. Malerba M, Ponticiello A, Radaeli A, Bensi G, Grassi V. Effect of twelve-months therapy with oral ambroxol in preventing exacerbations in patients with COPD. Double-blind, randomized, multicenter, placebo-controlled study (the AMETHIST Trial). Pulm Pharmacol Ther. 2004;17(1):27-34.
72. Kuang SG, Zhang HY, Zhang J, et al. [The effect of ambroxol on oxidation/antioxidant imbalance in AECOPD patients]. Zhong Hua Nei Ke Za Zhi. 2001;40(2):125-126. Chinese.

73. Lu Q, Yu J, Bao L, Ran T, Zhong H. Effects of combined treatment with ambroxol and ciprofloxacin on catheter-associated Pseudomonas aeruginosa biofilms in a rat model. Chemotherapy. 2013;59(1):51-56.

74. Chen CY, Liu HL. [The clinical efficacy of intravenous and bronchoalveolar lavage ambroxol for patients with bronchiectasis and infection]. Zhong Guo She Qu Yi Shi. 2013;15(6):128-129. Chinese.

75. Cao L, Chen Y, Zhao Y, et al. Effect of Myrtol standardized on mucus hypersecretion and clearance of Pseudomonas aeruginosa in a rat model of chronic obstructive pulmonary disease. Arzneimittelforschung. 2011;61(12):685-692.

76. Zhang XX, Shi T, Nie XH. Systematic review of standardized myrtol in the treatment of COPD. Zhong Guo Yao Ye. 2013;22(5):36-39.

77. Arai N, Kondo M, Izumo T, Tamaoki J, Nagai A. Inhibition of neutrophil elastase-induced goblet cell metaplasia by tiotropium in mice. Eur Respir J. 2010;35(5):1164-1171.

78. Tan YF, Zhang W, Yang L, Jiang SP. The effect of formoterol on airway goblet cell hyperplasia and protein Muc5ac expression in asthmatic mice. Eur Rev Med Pharmacol Sci. 2011;15(7):743-750.

79. Meyer T, Reitmeir P, Brand P, et al. Effects of formoterol and tiotropium bromide on mucus clearance in patients with COPD. Respir Med. 2011;105(6):900-906

80. ZhengYL, Zeng XL. [Therapeutic effect analysis of Ambroxol in combination with inhaled Combivent on acute exacerbation of chronic obstructive pulmonary disease]. Zhong Hua Lao Nina Yi Xue Za Zhi. 2014;33(11):1210-1211. Chinese.

81. Poole P, Black PN, Cates CJ. Mucolytic agents for chronic bronchitis or chronic obstructive pulmonary disease. Cochrane Database Syst Rev. 2012;8:CD001287.

82. World Health Organization Collaborating Centre for Tobacco or Health, Tobacco Control Office of Chinese Center for Disease Control and Prevention, Chinese Association on Tobacco Control Hospital Smoking Control Committee. [China clinical smoking cessation guidelines (2007 edition, the Tentative)]. Guo Ji Hu Xi Za Zhi. 2008;28(16):961-970. Chinese.

83. Respiratory Care Group of Chinese Thoracic Society. [Expert consensus on aerosol treatment]. Zhonghua Jie He He Hu Xi Za Zhi. 2013;37(11):805-808. Chinese.

84. Fink JB. Positioning versus postural drainage. Respir Care. 2002 47(7):769-777.

85. Chakravorty I, Chahal K, Austin G. A pilot study of the impact of high-frequency chest wall oscillation in chronic obstructive pulmonary disease patients with mucus hypersecretion. Int J Chron Obstruct Pulmon Dis. 2011;6:693-699.

86. Venturelli E, Crisafulli E, DeBiase A, et al. Efficacy of temporary positive expiratory pressure (TPEP) in patients with lung diseases and chronic mucus hypersecretion. The $\mathrm{UNIKO}^{\circledR}$ project: a multicentre randomized controlled trial. Clin Rehabil. 2013;27(4):336-346.
International Journal of COPD

\section{Publish your work in this journal}

The International Journal of COPD is an international, peer-reviewed journal of therapeutics and pharmacology focusing on concise rapid reporting of clinical studies and reviews in COPD. Special focus is given to the pathophysiological processes underlying the disease, intervention programs, patient focused education, and self management protocols.

\section{Dovepress}

This journal is indexed on PubMed Central, MedLine and CAS. The manuscript management system is completely online and includes a very quick and fair peer-review system, which is all easy to use. Visit http://www.dovepress.com/testimonials.php to read real quotes from published authors. 